\title{
HIV-1 reservoirs in elite controllers: clues for developing a functional cure?
}

\author{
"The advent of combination antiretroviral therapy revolutionized the \\ treatment of HIV-1 infection but has failed to deliver a definitive cure."
}

Megan E May', Abena K Kwaa' \& Joel N Blankson*,1

First draft submitted: 1 August 2017; Accepted for publication: 4 August 2017; Published online: 24 August 2017

The presence of replicationcompetent virus in elite controllers

The advent of combination antiretroviral therapy (cART) revolutionized the treatment of HIV-1 infection but has failed to deliver a definitive cure. The primary barrier to viral eradication is the latent reservoir. Resting memory $\mathrm{CD}^{+} \mathrm{T}$ cells are the best characterized cells in this reservoir; they are in a reversibly nonproductive state of infection [1] and will have to be eliminated, controlled by the immune system or permanently silenced if a cure is to be achieved.

Elite controllers (ECs) are patients who control HIV-1 replication without antiretroviral therapy [2]. One of the most fundamental questions regarding elite control is whether infection with defective virus or immune control of replication-competent virus is the mechanism behind this phenomenon in most patients. The answer to this question has major implications: if replication-competent virus is being controlled by host factors, then it suggests that these patients may in fact be a model of a functional cure of HIV-1. To address this question, investigators have looked at the viral reservoir in these patients. While some studies have shown that defective virus is present in some patients with longterm nonprogression or elite control [3], several groups have been able to culture replication-competent virus from some ECs [4-6]. Full-genome sequence analysis and phenotypic analyses have suggested that these isolates are fully pathogenic [4] and in a proof of concept study, virus cultured from ECs were shown to replicate vigorously and induce $\mathrm{CD} 4^{+}$T-cell depletion in humanized mice [7]. Transmission studies between patients with progressive disease (chronic progressors [CPs]) and ECs $[8,9]$ have also suggested that some of these patients are infected with replication-competent virus and in one case, it appears that an EC transmitted virus to a CP [9]. Finally, some ECs develop virologic progression over time [10] and an EC was shown to develop viremia after chemotherapy [11]. Taken together there is good evidence that some ECs are infected with replication-competent virus.

\section{KEYWORDS}

- antiviral drugs $\bullet$ CART $\bullet \mathrm{CD}^{+}$

T cells $\bullet$ elite controllers $\bullet$ HIV/AIDS

- immunity $\bullet$ latent reservoirs $\bullet$ viral replication 
“...while some elite controllers may be infected with defective virus, there is substantial evidence for the presence of replicationcompetent virus in others."

\section{Defining the reservoir in ECs}

The composition of the reservoir has also been studied and the frequency of latently infected $\mathrm{CD}^{+} \mathrm{T}$ cells in peripheral blood has been shown to be significantly lower in ECs than it is in patients with progressive disease on cART (CPs) [4]. The same finding holds true for total [6] and integrated [12] HIV-1 DNA and cell-associated HIV-1 RNA [13]. Sequence analysis has shown that there is much less diversity of proviral HIV-1 DNA clones in resting $\mathrm{CD}^{+} \mathrm{T}$ cells in ECs compared with CPs $[14,15]$ and a recent study showed that these identical sequences were particularly enriched in effector memory $\mathrm{T}$ cells [15]. Further studies will be needed in order to determine whether this low diversity is evidence of the clonal expansion that has been described in patients on cART [16] or due to early deposition of virus in the reservoir before selective pressure is exerted in primary infection. While Boritz and colleagues used integration site analysis to confirm clonal expansion of virus in two patients with low level viremia (viremic controllers [VCs]) [15], there is not a definitive proof that the same phenomenon occurs in ECs who inhibit viral replication to a more stringent degree. Nonetheless, in order to assess the functional significance of this low diversity in ECs, Bailey and colleagues analyzed Gag and Nef CD8 ${ }^{+}$T-cell epitopes in ECs with the protective HLA-B*57 allele. There was not a lot of evidence of virologic escape in these epitopes in proviral clones, however when they looked at plasma clones from the same patients they found that every single clone in every patient contained escape mutations $[17,18]$. Furthermore, in another study, the proviral clones were found to be ancestral to the plasma clones implying that they were more representative of the transmitted virus [19]. A recent study has confirmed this discordance between clones amplified from peripheral $\mathrm{CD}^{+} \mathrm{T}$ cells versus plasma in ECs and has also shown that the same pattern is not seen in CPs [15]. The universal presence of escape mutations in plasma virus suggests that there is ongoing viral replication in some compartment in these patients and that CD $8^{+}$ $T$ cells are exerting strong selective pressure on the virus. Interestingly, in studies that followed these patients over a 5-year period, it was found that evolution of proviral clones in peripheral $\mathrm{CD}^{+} \mathrm{T}$ cells was rare, whereas significant evolution due to synonymous mutations was seen in plasma clones from the same patients over the same period of time [19]. Evolution of plasma virus has been confirmed in another cohort of ECs [20] whereas no evolution was seen in plasma viral clones in patients on cART using the same methods [21]. The data suggest that there is a greater degree of ongoing viral replication in ECs than in patients on cART.

\section{Is there a compartment of ongoing viral replication in ECs?}

The source of the viral clones seen in plasma has not yet been established. The presence of escape mutations suggest that the viruses are produced in a compartment where $\mathrm{CD} 8^{+}$ $\mathrm{T}$ cells are present. CD $4^{+} \mathrm{T}$ cells in peripheral blood would appear to be a candidate. While the lack of evolution of proviral clones amplified from resting $\mathrm{CD}^{+}{ }^{+} \mathrm{T}$ cells may be evidence that most of these clones are defective, sequence analysis has shown that the degree of APOBEC mediated hypermutations present in these proviral clones is not different from that seen in clones amplified from CP resting $\mathrm{CD}^{+}{ }^{+} \mathrm{T}$ cells $[22]$. Furthermore, several studies have shown that activation of peripheral $\mathrm{CD}^{+}$ $T$ cells results in some level of viral transcription $[15,23]$ and in some cases production of replication-competent virus [4-6].

A recent study in the monkey model of elite control showed that viral replication was mostly restricted to $\mathrm{CD}^{+}$follicular helper $\mathrm{T}$ (TFH) cells in B-cell follicles in lymph nodes [24]. $\mathrm{CD}^{+} \mathrm{T}$ cells are mostly excluded from this compartment and the low frequency of these effector cells could potentially explain why there is ongoing viral replication. Similar findings were seen in a study that looked predominantly at VCs [15]. TFH cells accounted for more than $70 \%$ of infected lymph node cells in three $\mathrm{VCs}$ and interestingly, viral clones from these cells were more closely related to plasma clones than to clones from peripheral $\mathrm{CD} 4^{+} \mathrm{T}$ cells. If these findings are confirmed in ECs, it would provide strong evidence that the viral clones in plasma originate from TFH cells in lymphoid tissue. The low level of $\mathrm{CD}^{+} \mathrm{T}$ cells present in B-cell follicles may be able to exert enough selective pressure to explain the high frequency of escape mutants in plasma. Alternatively, the escape mutants may arise from the nongerminal center TFH cells which should be in close proximity of $\mathrm{CD}^{+} \mathrm{T}$ cells. 


\section{Attenuation of EC viral clones: cause or consequence?}

Many studies have looked at the individual viral proteins from EC plasma virus and shown some degree of attenuation compared with proteins from CPs $[25,26]$. This could possibly be because plasma clones are very distinct from proviral clones in ECs [15-17] but not in CPs [15]. The Gag and Nef plasma clones almost universally contain escape mutations in ECs $[17,18]$ and it is possible that the other viral proteins may also contain mutations that exert a fitness cost. It has been hypothesized that due to less viral replication in ECs, fewer compensatory mutations accumulate in viral proteins resulting in less fit virus [27]. This would suggest that the reduced fitness seen may be a consequence rather than a cause of elite control. In one study, multiple replicationcompetent isolates were cultured from peripheral CD4 ${ }^{+} \mathrm{T}$ cells from an EC and it was shown that an isolate that was similar in sequence to plasma viral clones had markedly reduced fitness compared with another isolate that resembled proviral clones [28]. More studies that focus on replication-competent virus are needed since these isolates appear to be more closely related to the ancestral viruses that were transmitted to the patient. The ratio of replication-competent virus to HIV proviral DNA is very low in CPs on cART [29] and if this holds true in ECs as well, it should be no surprise that it has been challenging to culture virus from these patients given their lower level of proviral DNA. Cultures of isolates that appear to be attenuated may not be representative of fully replication-competent virus that may exist at an even lower frequency. Even if replication-competent virus is obtained, the comparison of fitness of these isolates in ECs versus CPs should take into account the fact that viruses from most CPs have replicated for long periods of time before cART was initiated, leading to evolution to a more fit state, whereas EC virus archived in the reservoir does not appear to evolve [19]. This concept is perhaps best illustrated by a longitudinal study which found that while viruses from both HLA-B*57 longterm nonprogressors and CPs had relatively low levels of fitness in primary infection, the viral fitness increased over time in CPs but was relatively stable in long-term nonprogressors [30].

\section{Conclusion \& future perspective}

Taken together, while some ECs may be infected with defective virus, there is substantial evidence for the presence of replication-competent virus in others. This replication-competent virus appears to be restricted very early in the disease course by the immune system and this could potentially be recapitulated with the early initiation of cART in patients with progressive disease. There does appear to be low level ongoing replication in sanctuaries such as lymphoid tissue, but this could potentially be controlled if there were better ways of getting $T$ cells to penetrate these compartments. While ECs are not a perfect model for a functional cure because of the relatively high levels of inflammation seen in these patients, understanding how viral replication is controlled may lead to the design of an effective therapeutic vaccine.

\section{Financial \& competing interests disclosure}

This work was funded by NIH Grants 1R01AI120024 to JN Blankson and by the Johns Hopkins University Center for AIDS Research, an NIH-funded program (1P30A1094189). The authors have no other relevant affiliations or financial involvement with any organization or entity with a financial interest in or financial conflict with the subject matter or materials discussed in the manuscript apart from those disclosed.

No writing assistance was utilized in the production of this manuscript.

\section{References}

1 Eisele E, Siliciano RF. Redefining the viral reservoirs that prevent HIV-1 eradication. Immunity 37(3), 377-388 (2012).

2 Migueles SA, Connors M. Long-term nonprogressive disease among untreated HIV-infected individuals: clinical implications of understanding immune control of HIV. JAMA 304(2), 194-201 (2010).

3 Zaunders J, Dyer WB, Churchill M. The Sydney blood bank cohort: implications for viral fitness as a cause of elite control. Curr. Opin. HIV AIDS 6(3), 151-156 (2011).

4 Blankson JN, Bailey JR, Thayil S et al. Isolation and characterization of replicationcompetent human immunodeficiency virus type 1 from a subset of elite suppressors. J. Virol. 81(5), 2508-2518 (2007).

5 Lamine A, Caumont-Sarcos A, Chaix ML et al. Replication-competent HIV strains infect HIV controllers despite undetectable viremia (ANRS EP36 study). AIDS 21(8), 1043-1045 (2007).
6 Julg B, Pereyra F, Buzón M et al. Infrequent recovery of HIV from, but robust exogenous infection of activated $\mathrm{CD}^{+}{ }^{+} \mathrm{T}$-cells from HIV elite controllers. Clin. Infect. Dis. 51(2), 233-238 (2010).

7 Salgado M, Swanson MD, Pohlmeyer CW et al. HLA-B*57 elite suppressor and chronic progressor HIV-1 isolates replicate vigorously and cause $\mathrm{CD}^{+}{ }^{+} \mathrm{T}$ cell depletion in humanized BLT mice. J. Virol. 88(6), 3340-3352 (2014).

8 Bailey JR, O'Connell K, Yang HC et al. Transmission of human immunodeficiency 
virus type 1 from a patient who developed AIDS to an elite suppressor. J. Virol. 82(15), 7395-7410 (2008).

9 Buckheit RW, Allen TG, Alme A et al. Host factors dictate control of viral replication in two HIV-1 controller/chronic progressor transmission pairs. Nat. Commun. 3, 716 (2012).

10 Noel N, Lerolle N, Lécuroux C et al. Immunologic and virologic progression in HIV controllers: the role of viral "blips" and immune activation in the ANRS CO21 CODEX study. PLoS ONE 10(7), e0131922 (2015).

11 Watters SA, Mlcochova P, Maldarelli F, Goonetilleke N, Pillay D, Gupta RK. Sequential CCR5-tropic HIV-1 reactivation from distinct cellular reservoirs following perturbation of elite control. PLoS ONE 11(7), e0158854 (2016).

12 Graf EH, Mexas AM, Yu JJ et al. Elite suppressors harbor low levels of integrated HIV DNA and high levels of 2-LTR circular HIV DNA compared to HIV+ patients on and off HAART. PLoS Pathog. 7(2), e1001300 (2011).

13 Hatano H, Somsouk M, Sinclair E et al. Comparison of HIV DNA and RNA in gut-associated lymphoid tissue of HIVinfected controllers and non-controllers. AIDS 27(14), 2255-2260 (2013).

14 Bailey JR, Lassen KG, Yang HC et al. Neutralizing antibodies do not mediate suppression of human immunodeficiency virus type 1 in elite suppressors or selection of plasma virus variants in patients on highly active antiretroviral therapy. J. Virol. 80(10), 4758-4770 (2006).

15 Boritz EA, Darko S, Swaszek L et al. Multiple origins of virus persistence during natural control of HIV infection. Cell 166(4), 1004-1015 (2016).

16 Mullins JI, Frenkel LM. Clonal expansion of human immunodeficiency virus-infected cells and human immunodeficiency virus persistence during antiretroviral therapy. J. Infect. Dis. 215(Suppl. 3), S119-S127 (2017).

17 Bailey JR, Williams TM, Siliciano RF, Blankson JN. Maintenance of viral suppression in HIV-1-infected HLA-B*57+ elite suppressors despite CTL escape mutations. J. Exp. Med. 203(5), 1357-1369 (2006).

18 Bailey JR, Brennan TP, O’Connell KA, Siliciano RF, Blankson JN. Evidence of CD8 ${ }^{+}$ T-cell-mediated selective pressure on human immunodeficiency virus type 1 nef in HLA-B ${ }^{*} 57^{+}$elite suppressors. J. Virol. 83(1), 88-97 (2009).

19 O'Connell KA, Brennan TP, Bailey JR, Ray SC, Siliciano RF, Blankson JN. Control of HIV-1 in elite suppressors despite ongoing replication and evolution in plasma virus. J. Virol. 84(14), 7018-7028 (2010).

20 Mens H, Kearney M, Wiegand A et al. HIV-1 continues to replicate and evolve in patients with natural control of HIV infection. J. Virol. 84(24), 12971-12981 (2010).

21 Kearney MF, Spindler J, Shao W et al. Lack of detectable HIV-1 molecular evolution during suppressive antiretroviral therapy. PLoS Pathog. 10(3), e1004010 (2014).

22 Gandhi SK, Siliciano JD, Bailey JR, Siliciano RF, Blankson JN. Role of APOBEC3G/F-mediated hypermutation in the control of human immunodeficiency virus type 1 in elite suppressors. J. Virol. 82(6), 3125-3130 (2008).

23 Noel N, Peña R, David A et al. Long-term spontaneous control of HIV-1 is related to low frequency of infected cells and inefficient viral reactivation. J. Virol. 90 (13), 6148-6158 (2016).

24 Fukazawa Y, Lum R, Okoye AA et al. A B-cell follicle sanctuary permits persistent productive SIV infection in elite controllers. Nat. Med. 21(2), 132-139 (2015).

25 Miura T, Brockman MA, Schneidewind A et al. HLA-B57/B*5801 human immunodeficiency virus type 1 elite controllers select for rare gag variants associated with reduced viral replication capacity and strong cytotoxic T-lymphotye recognition. J. Virol. 83(6), 2743-2755 (2009).

26 Chen J, Tibroni N, Sauter D et al. Modest attenuation of HIV-1 Vpu alleles derived from elite controller plasma. PLoS ONE 10(3), e0120434 (2015).

27 Brockman MA, Brumme ZL, Brumme CJ et al. Early selection in Gag by protective HLA alleles contributes to reduced HIV-1 replication capacity that may be largely compensated for in chronic infection. J. Virol. 84(22), 11937-11949 (2010).

28 O'Connell KA, Hegarty RW, Siliciano RF, Blankson JN. Viral suppression of multiple escape mutants by de novo $\mathrm{CD} 8{ }^{+} \mathrm{T}$ cell responses in a human immunodeficiency virus-1 infected elite suppressor. Retrovirology 8, 63 (2011).

29 Eriksson S, Graf EH, Dahl V et al. Comparative analysis of measures of viral reservoirs in HIV-1 eradication studies. PLoS Pathog. 9(2), e1003174 (2013).

30 Navis M, Schellens I, van Baarle D et al. Viral replication capacity as a correlate of HLA B57/B5801-associated nonprogressive HIV-1 infection. J. Immunol. 179(5), 3133-3143 (2007). 